\title{
DESIGN OF THE PROTOTYPE LOW ENERGY BEAM TRANSPORT LINE FOR THE SPALLATION NEUTRON SOURCE *
}

\author{
D.W. Cheng, R.A. Gough, M.D. Hoff, R. Keller, M.A. Leitner, K.N. Leung, \\ J.W. Staples, M.D. Williams, \\ Earnest Orlando Lawrence Berkeley National Laboratory, Berkeley, CA 94720
}

\begin{abstract}
The design of the Spallation Neutron Source $(S N S)$ prototype low-energy beam transport (LEBT) system is discussed. This $L E B T$ must transfer $35 \mathrm{~mA}$ of $\mathrm{H}^{-}$current from the ion source outlet aperture to the entrance of the radio-frequency quadrupole $(R F Q)$. The plasma generator is a radio frequency-driven multicusp source, operated at $6 \%$ duty factor $(1 \mathrm{~ms}, 60 \mathrm{~Hz})$. The entire LEBT configuration is electrostatic, with a high-voltage extraction gap followed by two sets of einzel lenses. The second einzel lens will be split into four quadrants to permit the application of transverse steering and beam chopping fields. The $\mathrm{H}^{-}$ion source emits a gas flow into the LEBT that must be efficiently pumped to reduce stripping losses of the $\mathrm{H}^{-}$ions. Therefore, an efficient electrode design is incorporated to reduce the gas pressure between the electrodes. Alignment requirements and related issues will also be discussed.
\end{abstract}

\section{INTRODUCTION}

The Spallation Neutron Source front end systems, being built at the Lawrence Berkeley National Laboratory (LBNL), must supply a $2.5 \mathrm{MeV}, 28 \mathrm{~mA} \mathrm{H}^{-}$beam at $6 \%$ duty factor to a $1 \mathrm{GeV}$ linac that injects into an accumulating ring. This ring then delivers a $1 \mathrm{MW}$ average beam power to a neutron production target at 60 $\mathrm{Hz}$. This paper discusses the design of the low energy beam transport (LEBT) line of the front end accelerator system.

\section{REQUIREMENTS}

The LEBT is designed to transport $35 \mathrm{~mA}$ of a $65 \mathrm{keV} \mathrm{H}^{-}$ beam from an rf-driven source to the RFQ, operating at a $6 \%$ duty factor. It must match the beam to the RFQ entrance with a normalized emittance of less than $0.15 \pi$ $\mathrm{mm} \bullet \mathrm{mrad}$ and Twiss parameters, $\alpha=1.6$, and $\beta=6.5 \mathrm{~cm}$. The entire LEBT is electrostatic, with a high-voltage ( $~ 80$ $\mathrm{kV}$ ) extraction gap and an einzel lens configuration with beam chopping and steering capabilities incorporated into the second (G5) lens electrode. The entire package is approximately $10 \mathrm{~cm}$ in length. Figure 1 shows a cross-

\footnotetext{
*This research is sponsored by the Lockheed Martin Energy Research Corporation under the U.S. Department of Energy, Contract No. DEAC05-96OR22464, through the Lawrence Berkeley National Laboratory under contract No. DE-AC03-76SF00098.

'Email: dwcheng@lbl.gov
}

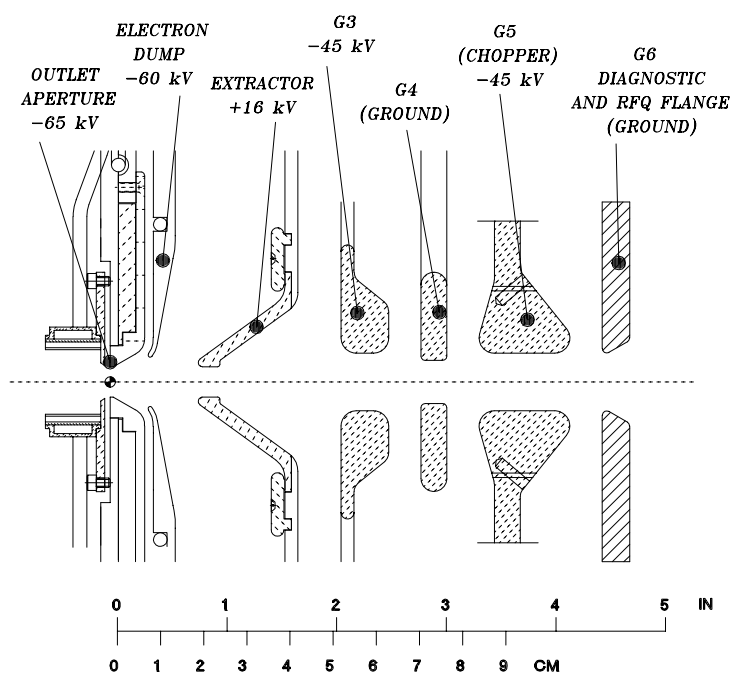

Figure 1. Cross section of the LEBT electrodes, with the ion source outlet aperture, electron dump, and RFQ endwall.

section of the lens configuration. Because of the limited space, voltage holding and creepage length along the surface of insulators must be taken into consideration. Table 1 summarizes the design parameters used. In addition, alignment for these electrodes must be held to a $\pm 0.05 \mathrm{~mm}$ tolerance in the radial direction, and $\pm 0.1 \mathrm{~mm}$ in the $z$ (beam) direction.

Table 1. Criteria for voltage holding used. *units of $d$ are $\mathrm{cm}$, units of $U$ are $\mathrm{kV}$

\begin{tabular}{r|c|c} 
& in Vacuum & in Air \\
\hline Gap: & $* d=\left(0.0141 U^{3 / 2}\right) / 10$ & $10 \mathrm{kV} / \mathrm{cm}$ \\
Insl. Surface: & $15 \mathrm{kV} / \mathrm{cm}$ & $8 \mathrm{kV} / \mathrm{cm}$
\end{tabular}

\section{ELECTRODE DESIGN}

\subsection{Extractor Electrode}

The extractor electrode consists of three sub-parts: the main stainless-steel "spider-arm", a retainer ring, and the aperture insert held in place by the ring (see Figure 1). The aperture insert is replaceable in case of accidental damage by hitting of the beam particles. Therefore, the aperture is designed to be accessible and replaceable without affecting the alignment of the entire LEBT assembly. We will use copper, as opposed to stainless steel, for the insert material because of its excellent thermal conductivity. We will also consider other 
materials, such as a 70\%/30\% tungsten-copper sintered material, which combines tungsten's structural integrity with copper's thermal properties.

\subsection{G3 and G5 Einzel Lenses}

The LEBT matching section consists of two "pseudo"einzel lenses: the aperture G3 and the split G5 lens. G5 is used for fast beam chopping[1]. The inner diameter of this lens has to be very narrow in order to achieve sufficient beam deflection with the available chopper power supplies. This contradicts the general rule that a small lens filling-factor (beam diameter/inner lens diameter) is required for good ion optics. Ion optics simulations have been performed to minimize beam emittance-growth due to aberrations caused by the lens configuration[2]. Figure 2 shows a SimIon 3D simulation of the $\mathrm{H}^{-}$beam passing through the LEBT. We have used the ion optics codes KOBRA 3D, IGUN[3] and AXCEL to optimize the LEBT lens arrangement.

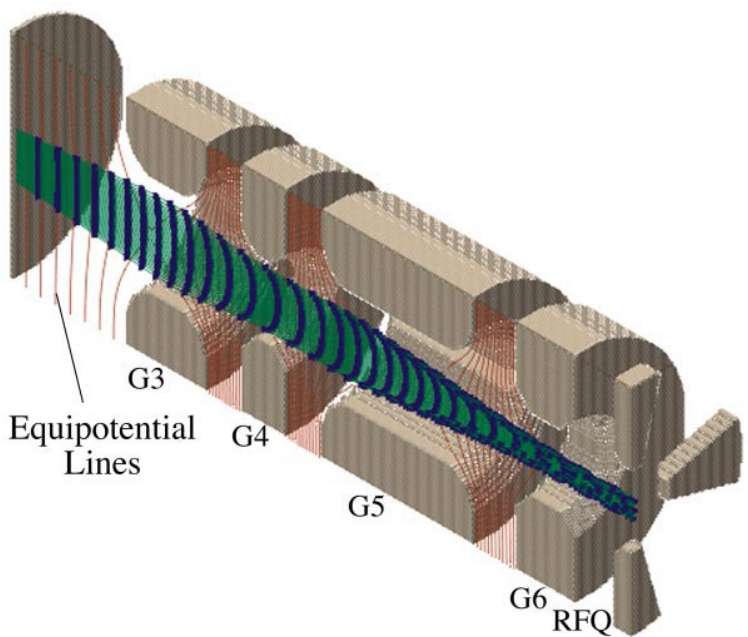

Figure 2. SIMION 3D simulation of the beam passing through the LEBT to the RFQ.

To allow beam chopping as well as beam steering in the $x$ - and $y$-directions lens G5 has been designed as a four-segmented aperture. It will be fabricated as a single piece with alignment holes drilled prior to wire-edm machining into the four segments. The pieces are then pinned with ceramic standoffs for voltage holding of $5 \mathrm{kV}$ max. A further discussion of its function can be seen in [1].

\subsection{Ground Electrode}

The electrode G4 has been designated as the main support structure, since it is fixed at ground potential. All other electrodes will be bench-mounted and pre-aligned to it. This whole, monolithic LEBT package facilitates easier alignment to the RFQ and ion source since now only one single component has to be adjusted. Figure 3 shows a blow-up assembly of the LEBT electrodes.

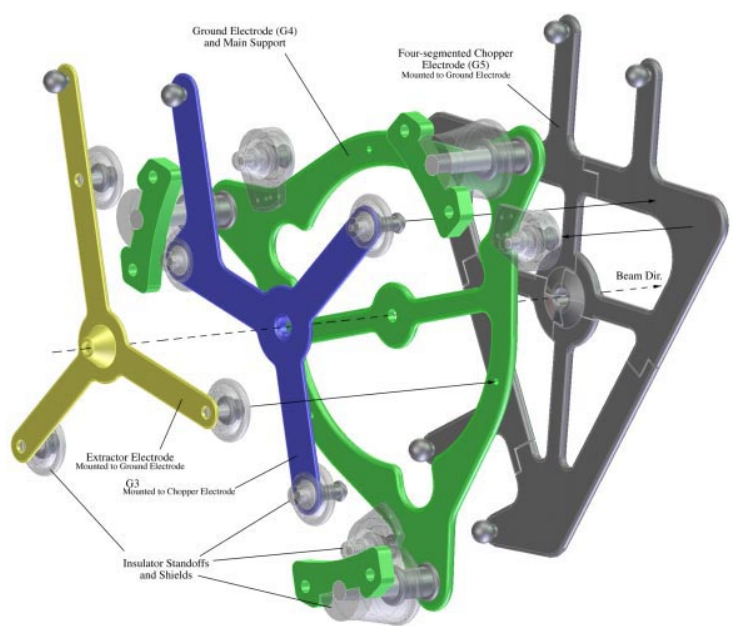

Figure 3. Blow-apart view of the LEBT electrode assembly.

\section{THE ELECTRODE ASSEMBLY}

The whole LEBT assembly is mounted to the ion source re-entrant cylinder as shown in Figure 4a. A three-point mounting scheme is employed with ceramic insulator posts standing between the ion source re-entrant cylinder biased at $-65 \mathrm{kV}$ and the electrode $\mathrm{G} 4$ on ground potential. Each electrode is held in place by using similar three ceramic post standoffs. Each standoff is shielded from a direct line of sight to the ion beam in order to prevent coating of, or sputtering on the insulator surfaces.

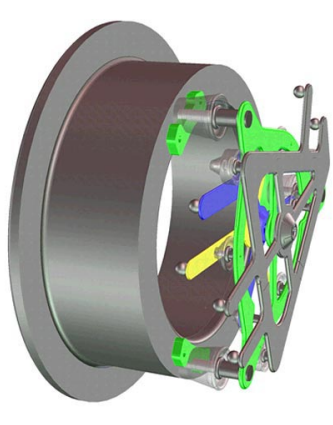

(a)

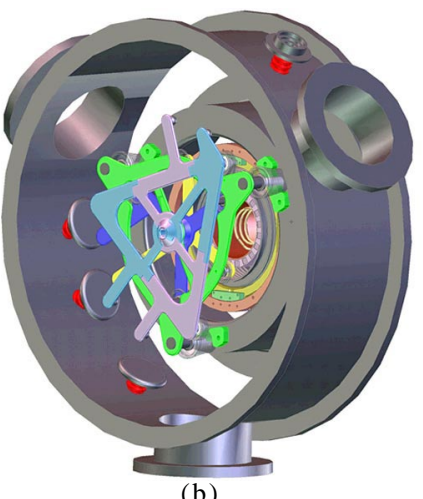

(b)
Figure 4. (a) LEBT assembly mounted to the source re-entrant cylinder, and (b) in a conceptual vacuum vessel.

The stainless-steel shields are glued to the ceramic standoffs with epoxy. The electrodes are then screwed to the metal shields. $2 \mathrm{~mm}$ shims are used in some locations to compensate for misalignment during the fabrication process.

Tests were conducted on two critical standoffs: the main standoff from the $-65 \mathrm{kV}$ source potential to the ground (G4) lens, and the standoff from ground to the -55 $\mathrm{kV}$ chopper lens (G4 to G5), see Figure 5. The inside geometry of the shields was fabricated and each assembly was hi-potted. Both tests were successful: the standoffs 


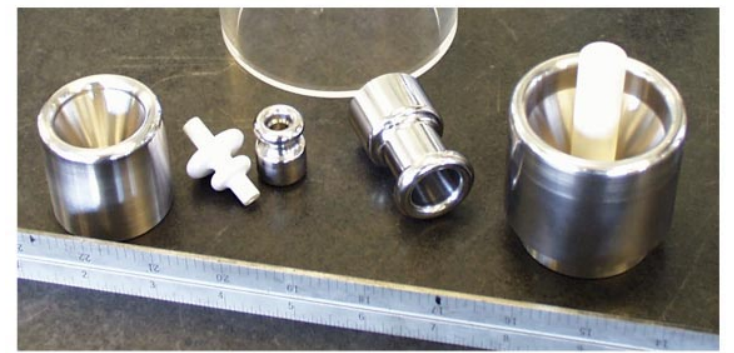

Figure 5. Insulator standoffs prior to testing. Shown are (left) the chopper to ground (G5-G4) insulators, and (right) the main insulator (main support to $-65 \mathrm{kV}$ source potential

held $15 \%$ more than their design voltages after minimal conditioning.

\section{VACUUM VESSEL}

A noticeable departure of this design from traditional LEBT structures is the lack of gradient rings and stacked insulators. The main insulator will be a cast silica-filled epoxy structure, insulating the ion source re-entrant cylinder at $-65 \mathrm{kV}$ from the ground potential of the vacuum vessel. Its cross-sectional shape is similar to a horizontal "S" and is shown in Figure 6. Besides reducing the length of the ion-source re-entrant cylinder, this design also provides a wider-open geometry for improved pumping.

Triple-point protection consists of a brass screen that is cast into the epoxy, allowing the thread inserts for the mounting bolts to remain in a field-free region at the source re-entrant cylinder flange. The flange at ground potential is of a Kofoid design[4]. ANSYS finite element simlulations verified electrical potentials and gradients, and RASNA finite element runs have been used to determine the structural loading. Deflection tests will also be performed on this insulator under vacuum loading to determine the amount of shim necessary for correct alignment of the LEBT assembly.

The vacuum vessel consists of a $3 / 16$ " thick stainlesssteel chamber, 28 " diameter by 9" deep, with three 10 " pumping ports and high-voltage feedthroughs for the

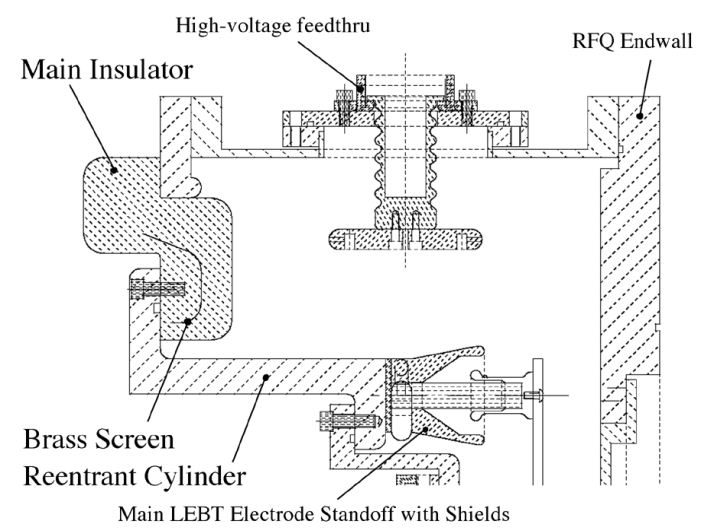

Figure 6. The LEBT assembly in a conceptual view of the vacuum vessel.
LEBT electrodes. See Figure $4 b$ for a conceptual view of the vessel containing the LEBT.

The main LEBT-assembly flange is movable under vacuum load. This allows on-line alignment of the ion source and the LEBT as an entire package to the RFQ entrance aperture. Screw-jacks will be mounted to the main insulator flange in the $x$ - and $y$-directions, and will be manually actuated with long shafts. The movement under vacuum load is accomplished by using an O-ring seal and friction-free teflon-impregnated pads upon which the flange rests. The weight of the ion source/LEBT package is held by flange bolts mounted on Belleville washers, which are tightened to a degree that allows movement without loosening the bolts.

\section{FABRICATION}

Detail design of the LEBT components is in progress; fabrication will start in the beginning of April 1999. The LEBT is scheduled to come on-line along with the ion source and a prototype section of the RFQ for testing in the summer of 1999.

\section{ACKNOWLEDGMENTS}

The authors would like to thank Russell Wells and Gary Koehler for their expertise, and Sam Mukherjee, Peter Luft, and John Pruyn for their design effort. Additional thanks go to Alessandro Ratti, Jim Greer, and Bill Abraham for their input, and their challenge of making a huggable LEBT become a reality.

\section{REFERENCES}

[1] J.W. Staples, J.J. Ayers, D.W. Cheng, J.B. Greer, M.D. Hoff, A. Ratti, "The SNS Four-Phase LEBT Chopper", these proceedings.

[2] M.A. Leitner, D.C. Wutte, K.N. Leung, "Simulation of the Low Energy H- Injector into the National Spallation Neutron Source Radio Frequency Quadrupole Accelerator", Rev. of Sci. Instrum., 69, 965 (1998).

[3] R. Becker and H. Hermannsfeldt, Rev. Sci. Instrum. 63, 2756 (1992).

[4] Kofoid, M.J., "Effect of metal dielectric junction phenomena on high-voltage breakdown over insulators", AIEE Trans. Power Apparatus and Systems, 79, 999-1004 (Dec. 1960). 